\title{
Prevalence of otitis media with effusion in children with bilateral sensorineural hearing loss
}

\author{
V K Das
}

\begin{abstract}
A cohort of 164 children born within the defined boundaries of greater Manchester during the years 1981 to 1984 inclusive were identified as having bilateral sensorineural hearing loss, giving a prevalence of $1 \cdot 2 / 1000$ population or $1 / 817$ births. Ninety three children developed an additional conductive hearing loss secondary to otitis media with effusion lasting more than three months and 39 of these $(42 \%)$ required surgical treatment. Those with congenital infections, adverse perinatal factors, and chromosomal abnormalities seemed to develop more conductive hearing problems than those in whom the aetiology was infective. Close audiology follow up is essential for effective treatment of children with sensorineural hearing loss.
\end{abstract}

Otitis media with effusion is one of the commonest ailments of childhood. The pathophysiology is poorly understood, but negative middle ear pressure caused by eustachian tube dysfunction seems to be the cause. Immunological factors may also play a part.

\section{Patients and methods}

The study was undertaken as part of a large epidemiological and investigative study of children born from 1981 to 1984 inclusive in the defined geographical area of greater Manchester who were diagnosed as having bilateral sensorineural hearing loss. ${ }^{1}$ After the diagnosis of sensorineural hearing loss, the patients were investigated to establish the possible aetiology of the hearing loss. Detailed medical and family histories were obtained. Clinical examination was carried out to look for any dysmorphic features or associated anomalies. Information was obtained from obstetricians and paediatricians. Serological investigations were undertaken to see if there was evidence of congenital rubella, cytomegalovirus, toxoplasmosis, and herpes simplex infection. Thyroid function tests (concentrations of triiodothyronine, thyroxine, and thyroid stimulating hormone), electrocardiography, skull radiography, and urine examination and culture for cytomegalovirus were also carried out. The patients' eyes were examined at the Manchester Royal Eye Hospital for visual acuity, site of puncta, colour of iris, corneal or lenticular opacities, and fundoscopy was carried out.

Patients with a mean bilateral sensorineural hearing loss of $30 \mathrm{~dB}$ or more in the better ear were included in this part of the study.
Longitudinal follow up was undertaken after appropriate amplification had been supplied. Conductive hearing loss was diagnosed if the mean conductive loss of $20 \mathrm{~dB}$ or more was present for any period longer than three months, between 1981 and 1987.

Audiology assessment was carried out by pure tone audiometry within the frequency range of $250 \mathrm{~Hz}$ to $4 \mathrm{kHz}$. Behavioural hearing tests and brainstem evoked response audiometry were used if pure tone audiometry was not possible because of immaturity or developmental delay. The results were converted into equivalent $\mathrm{dB}$ values using conversion tables. ${ }^{2}$ The cases were divided into two groups: mean hearing loss of less than $80 \mathrm{~dB}$ and mean hearing loss of $80 \mathrm{~dB}$ or more. Otoscopy and tympanometry were carried out throughout the follow up period in all cases.

\section{Results}

A total of 164 cases were diagnosed as having bilateral sensorineural loss, with a loss of $30 \mathrm{~dB}$ or more in the better ear. This gave a prevalence of $1 \cdot 2 / 1000$ births in the population, or $1 / 817$ births. The cases were divided into nine aetiological groups (table 1).

Ninety three patients (57\%) had, in addition, conductive hearing loss secondary to otitis media with effusion, which had lasted for a period of three months or more during the period up to 1987 . All patients were followed up every three to six months as necessary, and 39 of the patients $(24 \%)$ required surgical treatment (table 3). This comprised myringotomy with or without insertion of a ventilation tube, or adenoidectomy, or tonsillectomy, or a combination. The distribution of patients with conductive hearing loss according to aetiology is shown in table 2. Adverse perinatal factors were associated with preterm birth, and chromosomal anomalies consisted of trisomy 13 (Patau's syndrome), trisomy 18 (Edward's syndrome), and other rare partial trisomies or abnormalities.

Several children were not operated on because of a medical contraindication-for example, congenital heart disease, respiratory problems, and chromosomal abnormalities. No child was operated on when less than 1 year old.

Conductive hearing loss was not significantly associated with the age of diagnosis of deafness, sex, or the degree of hearing loss, although the parents and the peripatetic teachers of the deaf who took part in the follow up made significantly more requests for assessment of hearing when a child had a hearing loss of $80 \mathrm{~dB}$ or more. 
Table 1 Aetiology of bilateral sensorineural hearing loss by year of birth

\begin{tabular}{|c|c|c|c|c|c|c|}
\hline \multirow[t]{2}{*}{ Aetiological group } & \multicolumn{6}{|c|}{ Year of birth } \\
\hline & 1981 & 1982 & 1983 & 1984 & Total & No $(\%)$ \\
\hline Rubella & 2 & 2 & 4 & 1 & 9 & 5 \\
\hline Cytomegalovirus & 1 & 3 & 1 & 2 & 7 & 4 \\
\hline Adverse perinatal factors & 6 & 8 & 7 & 3 & 24 & 15 \\
\hline Meningitis & 2 & 2 & 3 & 3 & 10 & 6 \\
\hline Genetic abnormality & 13 & 7 & 10 & 3 & 33 & 20 \\
\hline Chromosomal anomaly & 3 & 0 & 1 & 2 & 6 & 4 \\
\hline Unknown & 26 & 10 & 12 & 12 & 60 & 37 \\
\hline Syndrome & 4 & 1 & 1 & 0 & 6 & 4 \\
\hline Miscellaneous & 0 & 3 & 2 & 4 & 9 & 5 \\
\hline Total & 57 & 36 & 41 & 30 & 164 & 100 \\
\hline
\end{tabular}

Table 2 Number of patients from each aetiological group who developed otitis media with effusion, and number who required surgical treatment

\begin{tabular}{lccc}
\hline Aetiological group & $\begin{array}{l}\text { Total No } \\
\text { in group }\end{array}$ & $\begin{array}{l}\text { No with otitis } \\
\text { media with effusion }\end{array}$ & $\begin{array}{c}\text { No requiring } \\
\text { surgical treatment }\end{array}$ \\
\hline Rubella & 9 & 7 & 3 \\
Cytomegalovirus & 7 & 6 & 2 \\
Adverse perinatal factors & 24 & 18 & 10 \\
Meningitis & 10 & 4 & 1 \\
Genetic abnormality & 33 & 15 & 5 \\
Chromosomal anomaly & 6 & 5 & 0 \\
Unknown & 60 & 4 & 17 \\
Syndrome & 6 & 7 & 1 \\
Miscellaneous & 9 & 93 & 0 \\
\hline Total & 164 & & 39 \\
\hline
\end{tabular}

Table 3 No of children with additional conductive hearing loss that required surgical treatment

\begin{tabular}{lll}
\hline $\begin{array}{l}\text { Degree of hearing } \\
\text { loss }\end{array}$ & $\begin{array}{l}\text { No with conductive } \\
\text { loss }\end{array}$ & $\begin{array}{l}\text { No requiring } \\
\text { surgical treatment }\end{array}$ \\
\hline$<80 \mathrm{~dB}$ & 40 & 17 \\
$\geqslant 80 \mathrm{~dB}$ & 53 & 22 \\
\hline Total & 93 & 39 \\
\hline
\end{tabular}

The patients with congenital infections, adverse perinatal factors, and chromosomal abnormalities seemed to have more conductive problems, but the numbers are too small for statistical analysis.

\section{Discussion}

Additional conductive hearing loss, which may be fluctuating, can cause appreciable problems in monitoring adequate amplification. The problems may not only be among patients with severe and profound hearing loss in whom the hearing may be almost impossible to amplify, but also occur in those with mild to moderate hearing loss. Brooks reported a prevalence of otitis media with effusion of one in five in a study of children at 5 years of age in residential schools for the deaf. ${ }^{3}$ This prevalence was similar to that reported in normal children at a similar age. He found that at 11 years of age $7 \%$ of children with impaired hearing were still suffering from otitis media with effusion compared with $2 \%$ of normal children. Other studies have reported a higher prevalence of middle ear dysfunction in children with sensorineural hearing loss. ${ }^{4-6}$ It is impossible to compare the present longitudinal study with any cross sectional study for prevalence or morbidity patterns.

In a longitudinal study reported by Jordan of 1191 normal children observed for five years,
$29 \cdot 6 \%$ had or developed otoscopic abnormality in one or both ears during the study period, and in $9.3 \%$ the visibility of the ear drum was unsatisfactory. ${ }^{7}$

In the present study the age of the children ranged between 2 and 6 years. The high prevalence of middle ear disease may be a reflection of the close follow up and longitudinal nature of the study, but a quarter of the children had significant problems requiring operation. Although only a few children had congenital infection with rubella and cytomegalovirus their inability to get rid of the relevant virus has been attributed to an undefined abnormality of the cellular immune system. These factors may increase their susceptibility to persistent otitis media with effusion.

The group with adverse perinatal factors is of interest. Surfactant deficiency causing eustachian tube dysfunction has been suggested as being one of the factors in the aetiology of otitis media with effusion. ${ }^{8}$ Surfactant deficiency in the respiratory system is common among preterm babies, and they have additional deficiency and immaturity of the immune system that increases their susceptibility to infections. These three factors may lead to poor or disturbed mucociliary function within the middle ear cleft and eustachian tube, which may be the main pathophysiological factor increasing the susceptibility of otitis media with effusion in this group.

\section{CONCLUSION}

A high incidence of conductive hearing loss in children with bilateral sensorineural hearing loss was found, but the longitudinal nature of the study may be partly responsible for this. Almost a quarter of the children required surgical treatment. Close audiological follow up supported by otological services is essential for 
the effective management of children with sensorineural hearing impairment.

I thank Emeritus Professor I G Taylor for his guidance, and the following for their help: Mrs M Hostler, Dr I Tucker Dr V Newton, Mr M Vidler, otolaryngologists, clinical medical officers, the Services for the Hearing Impaired, and Mrs P Williams.

1 Das VK. Aetiology of bilateral sensorineural deafness in children. F Laryngol Otol 1988;102:975-80.

2 Nolan $M$. Guidance on interpretation of information from a sound level meter. Fournal of British Association of Teachers of the Deaf 1978;2:169-73.

3 Brooks DN. Impedance bridge studies on normal hearing and hearing impaired children. Acta Otorhinolaryngol Belg 1974;28:140-5.

4 Porter TA. Otoadmittance measurements in a residential population. Am Ann Deaf 1974;119:47-52.

5 Mehta D, Erlich M. Serous otitis media in a school for the deaf. Volta Review 1978;80:75-80.

6 Stool SE, Craig HB , Laird MA. Screening for middle ear disease in a school for the deaf. Ann Otol Rhino Laryngol 1980;68(suppl):172-7.

7 Jordan RE. Epidemiology of otitis media. In: Glorig A Gerwin KS, eds. Otitis media. Springfield: Thomas, 1972.

8 Hills BA. Analysis of eustachian surfactant and its function as a release agent. Archives of Otolaryngology 1984;110:3-9. 